\title{
Prevalence of chronic cough and phlegm among male cigar and pipe smokers: results of the Scottish Heart Health Study
}

\author{
Colin A Brown, Mark Woodward, ${ }^{\star}$ Hugh Tunstall-Pedoe
}

\begin{abstract}
Background-Previous studies investigating the effect of cigar or pipe smoking on the occurrence of chronic cough and chronic phlegm have reported prevalences among cigar and pipe smokers lying between those of non-smokers and current cigarette smokers. This study uses data on previous cigarette consumption, current cigar or pipe consumption, and biochemical markers of smoking to provide a detailed analysis of chronic cough and chronic phlegm among cigar and pipe smokers.

Methods-A total of 10359 men and women aged 40-59 years were sampled for the Scottish Heart Health Study between 1984 and 1986. Prevalence of chronic cough and chronic phlegm among male cigar and pipe smokers (non-cigarette smokers) was compared with those who had never smoked, between ex-smokers of cigarettes and those who had never smoked cigarettes, between cigar-only and pipe-only smokers, and by cigar or pipe consumption levels.
\end{abstract}

Results-In all, 463 ex-smokers of cigarettes and 154 who had never smoked cigarettes were cigar or pipe smokers; 1080 had never smoked any form of tobacco. Ex-cigarette smokers smoked and inhaled more than those who had never smoked cigarettes. Among the excigarette smokers, cigar or pipe smokers had 1.63-1.71 times the prevalence of both chronic cough and chronic phlegm than those who had never smoked (1.31-1.36 among cigar only smokers; 2.23-2.84 among pipe only smokers). A strong positive dose-response effect was found between the prevalence of symptoms and cigar or pipe consumption. Conclusions-Cigar and pipe smokers have a higher prevalence of chronic cough and phlegm than those who have never smoked, and the difference is more marked in pipe-only smokers than in cigar-only smokers. Both categories show a positive dose-response effect. Among cigar and pipe smokers, excigarette smokers have a higher prevalence of symptoms than those who have never smoked cigarettes, which may be because they inhale more or may be attributable to previous cigarette smoking.

(Thorax 1993;48:1163-1167)
Few studies have investigated the effect of cigar and pipe smoking on the prevalence of respiratory symptoms and mortality from chronic bronchitis. Those studies that have investigated this have found that cigar and pipe smokers tend to have levels of symptoms between those of non-smokers and current cigarette smokers, ${ }^{1}$ with levels closer to those of the non-smokers ${ }^{2-4}$ in most cases. Studies looking only at pipe smokers have mixed findings. The prevalence of chronic bronchitis amongst pipe smokers has been reported as being higher than both non-smokers and cigarette smokers, ${ }^{5}$ a little above non-smokers, ${ }^{6}$ and the same as non-smokers. ${ }^{7}$ Doll and Peto $^{8}$ who studied mortality from chronic bronchitis found cigar and pipe smokers to have significantly higher mortality than nonsmokers. Densen $e t a l^{2}$ and Haenszel and Hougen $^{1}$ found a positive dose-response effect between cigar and pipe consumption and respiratory symptoms. However, Dean $e t$ $a l^{9}$ showed only prevalence of morning cough to be significantly higher among cigar and pipe smokers than non-smokers, while Alderson et $a l^{10}$ found no difference in the prevalence of respiratory symptoms between the two groups.

This paper uses cross sectional data from the Scottish Heart Health Study (SHHS) ${ }^{11} 12$ to investigate the effect of cigar smoking, pipe smoking, or both on the prevalence of chronic cough and chronic phlegm amongst men. Information on cigarette smoking status enables us to consider the effect on the respiratory symptoms of cigar and pipe smoking for both ex-cigarette smokers and subjects who have never been regular cigarette smokers. Three biochemical markers of tobacco consumption-carbon monoxide, thiocyanate, and cotinine-are used to give objective measures of self reported tobacco consumption and indirect evidence of inhalation.

\section{Methods}

The data used in this study were collected as part of the baseline SHHS which has been well documented elsewhere. ${ }^{13}$ Briefly, a sample of 10359 men and women, aged 40-59 years, were randomly selected from 22 districts across Scotland between 1984 and 1986. An extensive questionnaire, to be completed at home, was sent to each subject together with an appointment to attend a survey clinic for a physical examination. The data presented in this paper come from three sections of the questionnaire and from mea16 February 1993

Revised version received

17 March 1993

Accepted 6 July 1993 
surements taken during the examination. From the questionnaire, data from the personal history section, the British Medical Research Council (MRC) respiratory questionnaire, ${ }^{14}$ and the World Health Organisation standard smoking questions ${ }^{15}$ were examined. Occupational social class was determined by the definitions suggested by the Office of Population Censuses and Surveys. ${ }^{16}$ Expired air carbon monoxide levels were measured using a model 2000 Portable Carbon Monoxide Ecolyser (Analyses Automation Ltd) or an EC50 Carbon Monoxide Monitor (Bedfont Technical Instruments Ltd), instruments which have been shown to produce equivalent results. ${ }^{17} \mathrm{~A}$ blood sample was taken for estimation of serum thiocyanate with a COBAS Bioanalyser and serum cotinine by gas liquid chromatography. ${ }^{18}$

\section{DEFINITIONS OF TERMS}

Chronic respiratory symptoms were defined according to standard MRC definitions, ${ }^{14}$ chronic cough being cough first thing in the morning or at any time during the day or night for as much as three months each year, and chronic phlegm being the production of phlegm from the chest first thing in the morning or at any time during the day or night for as much as three months each year.

A cigarette smoker was defined as one who reported current regular or occasional cigarette smoking, an ex-cigarette smoker as one who was a cigarette smoker, and a nevercigarette smoker one who reported no regular or occasional cigarette smoking. A noncigarette smoker was either an ex-cigarette or never-cigarette smoker, a cigar or pipe smoker one who reported current regular or occasional smoking of cigars, pipes, or both, and a never-smoker was a never-cigarette smoker who has also never been a cigar or pipe smoker. A non-smoker or control was a non-cigarette smoker who was also not a cigar or pipe smoker. Cigar consumption was divided into three groups: light $(\leqslant 2$ cigars/day), moderate (3-4 cigars/day), and heavy ( $>4$ cigars/day), and pipe consumption was divided into two approximately equal groups: light ( $\leqslant 2$ ounces tobacco/week), and heavy ( $>2$ ounces tobacco/week).

\section{STUDY AND CONTROL GROUPS}

In the SHHS there were only 17 women who were cigar or pipe smokers; as this is such a

Table 1 Mean (SD) cigar, pipe and previous cigarette consumption by cigar and pipe smoking status among ex-cigarette smokers and never-cigarette smokers

\begin{tabular}{|c|c|c|c|c|}
\hline & $n$ & $\begin{array}{l}\text { Cigar } \\
\text { consumption } \\
\text { (no/week) }\end{array}$ & $\begin{array}{l}\text { Pipe } \\
\text { consumption } \\
\text { (ounces/week) }\end{array}$ & $\begin{array}{l}\text { Previous daily } \\
\text { cigarette } \\
\text { consumption }\end{array}$ \\
\hline \multicolumn{5}{|l|}{ Ex-cigarette smokers: } \\
\hline Cigar-only smokers & 294 & $18(19)$ & - & $22(12)$ \\
\hline Pipe-only smokers & 86 & - & $3 \cdot 2(1 \cdot 5)$ & $24(16)$ \\
\hline Cigar and pipe smokers & 83 & $8(13)$ & $2 \cdot 8(2 \cdot 0)$ & $24(13)$ \\
\hline \multicolumn{5}{|l|}{ Never-cigarette smokers: } \\
\hline Cigar-only smokers & 103 & $5(9)$ & - & - \\
\hline Pipe-only smokers & 27 & - & $2 \cdot 3(1 \cdot 3)$ & - \\
\hline Cigar and pipe smokers & 24 & $3(5)$ & $1.9(1.2)$ & - \\
\hline
\end{tabular}

small number it was decided to restrict all analyses to men. Of the 1009 men who currently smoked cigars, pipes, or both, 392 also smoked cigarettes. These 392 were excluded from the analysis to avoid the confounding effects of cigarette consumption, leaving a study group of 617 . There were 2474 men who were non-smokers according to their self report, of whom 37 were identified as probable deceivers by biochemical evidence ${ }^{19}$ and were excluded. A further 86 men who were current non-smokers but had previously smoked cigars, pipes, or both were also excluded, leaving a control group of 2351 non-smokers.

\section{STATISTICAL ANALYSIS}

The significance of the differences between various group means and symptom preva- $\stackrel{\oplus}{\infty}$ lences were compared by $t$ tests and $\chi^{2}$ tests $\vec{\perp}$ as appropriate. One way analysis of variance was used to test for a linear trend in the biochemical markers across the cigar consumption groups. ${ }^{20}$

\section{Results}

\section{SMOKING CHARACTERISTICS}

Cigar, pipe, and previous cigarette consumption for the study group related to previous cigarette smoking habit is shown in table 1. Cigar and pipe consumption were significantly greater $(p<0.001$ and $p<0.01$, respectively) among ex-cigarette smokers than in never-cigarette smokers. The heavy consumption group had smoked an average of about eight cigarettes/day more than the light consumption group for both cigar-only and pipe-only smokers $(\mathrm{p}<0.01$ and $\mathrm{p}<0.05$, respectively).

\section{BIOCHEMICAL MEASUREMENTS OF TOBACCO} CONSUMPTION

The relation between cigar and pipe consumption and the three biochemical markers 8 of tobacco consumption is shown in the figure. The biochemical markers were higher 의 among ex-cigarette smokers than never- $D$ cigarette smokers in each cigar and pipe consumption group, although the differences $N$ were statistically significant only in the light consumption groups. There was a significant 0 positive linear relationship $(p<0.001) \mathrm{W}$ between the biochemical markers and cigar consumption, except for carbon monoxide, $\stackrel{\circ}{\square}$ among never-cigarette smokers. There was also a significant difference between light and heavy pipe smokers, except for carbon monoxide and cotinine, among ex-cigarette smokers.

\section{PREVALENCE OF CHRONIC COUGH AND} CHRONIC PHLEGM

The prevalences of chronic cough and phlegm for each smoking category by previous smoking habit are shown in table 2 . Cigar and pipe smokers had a higher prevalence of both symptoms than the control group of non-smokers, except that the prevalences for chronic phlegm were almost identical among 
Table 2 Prevalence (\%) of chronic cough and chronic phelgm by cigar and pipe smoking status among ex-cigarette smokers and never-cigarette smokers (numbers of cases in parentheses

\begin{tabular}{|c|c|c|c|c|}
\hline & \multicolumn{2}{|l|}{ Chronic cough } & \multicolumn{2}{|c|}{ Chronic phlegm } \\
\hline & $\begin{array}{l}\text { Ex-cigarette } \\
\text { smoker }\end{array}$ & $\begin{array}{l}\text { Never-cigarette } \\
\text { smoker }\end{array}$ & $\begin{array}{l}\text { Ex-cigarette } \\
\text { smoker }\end{array}$ & $\begin{array}{l}\text { Never-cigarette } \\
\text { smoker }\end{array}$ \\
\hline Non-smokers & $7 \cdot 9(97)$ & $6 \cdot 2(65)$ & $10 \cdot 9(135)$ & $8 \cdot 1(85)$ \\
\hline Cigar or pipe smokers & $10 \cdot 6(48)$ & $9 \cdot 5(14)$ & $13 \cdot 2(59)^{\star \star}$ & $7 \cdot 9(12)$ \\
\hline Cigar-only & $8 \cdot 1(23)$ & $10 \cdot 2(10)$ & $11 \cdot 0(31)$ & $8 \cdot 9(9)$ \\
\hline Pipe-only & $17 \cdot 6(15)^{\star \star}$ & $11 \cdot 1(3)$ & $18 \cdot 1(15)^{\star}$ & $7 \cdot 4(2)$ \\
\hline Cigar and pipe & $12 \cdot 2(10)$ & $4 \cdot 3(1)$ & $16 \cdot 0(13)$ & $4 \cdot 3(1)$ \\
\hline
\end{tabular}

${ }^{\star} \mathrm{p}<0.05,{ }^{\star \star} \mathrm{p}<0.01\left(\chi^{2}\right.$ test for differences in proportions between controls (neversmokers) and cigar or pipe smokers, cigar-only smokers, pipe-only smokers, and cigar and pipe smokers). those who had never smoked cigarettes. For further comparison, the prevalences of both chronic cough and phlegm among current cigarette smokers in the SHHS (32\% from 496 cases and $31 \%$ from 479 cases respectively) are about three times those for cigar or pipe smokers. Chronic cough is more prevalent than chronic phlegm in both cigar or pipe smokers and controls. There was no significant effect of age or social class on the prevalence of cough or phlegm.

Among the cigar and pipe smokers the highest prevalences of both symptoms were for pipe-only smokers, except for chronic phlegm among those who had never smoked cigarettes which was most common among cigar-only smokers. The prevalences of both chronic cough and phlegm were higher among ex-cigarette smokers than never-cigarette smokers in all categories except for chronic cough among cigar-only smokers. For ex-cigarette smokers the prevalences of both symptoms were higher in each smoking category than in the control group $(p<0.05$ for cigar and pipe smokers and pipe-only smokers). For never-cigarette smokers, where the numbers are smaller, the corresponding differences were less marked, with some categories of cigar and pipe smokers having a lower prevalence of symptoms than the control group.

The dose-response effect of cigar and pipe consumption on the prevalence of both chronic cough and phlegm is shown in table 3. Among cigar-only smokers who previously smoked cigarettes there was a higher prevalence of chronic cough $(p<0.05)$ and chronic phlegm in the heavy consumption

Table 3 Prevalence (\%) of chronic cough and chronic phlegm by cigar and pipe consumption (numbers of cases in parentheses)

\begin{tabular}{|c|c|c|c|c|}
\hline & \multicolumn{2}{|c|}{ Chronic cough } & \multicolumn{2}{|c|}{ Chronic phlegm } \\
\hline & $\begin{array}{l}\text { Ex-cigarette } \\
\text { smoker }\end{array}$ & $\begin{array}{l}\text { Never-cigarette } \\
\text { smoker }\end{array}$ & $\begin{array}{l}\text { Ex-cigarette } \\
\text { smoker }\end{array}$ & $\begin{array}{l}\text { Never-cigarette } \\
\text { smoker }\end{array}$ \\
\hline $\begin{array}{l}\text { Non-smokers } \\
\text { Cigar-only smokers }\end{array}$ & $7 \cdot 9(97)$ & $6 \cdot 2(65)$ & $10.9(135)$ & $8 \cdot 1(85)$ \\
\hline $\begin{array}{l}<2 \text { cigars/day } \\
3-4 \text { cigars/day } \\
>4 \text { cigars/day }\end{array}$ & $\begin{array}{c}5 \cdot 4(8) \\
4 \cdot 0(2) \\
18 \cdot 0(11)^{\star}\end{array}$ & $\begin{array}{c}12 \cdot 2(9) \\
12 \cdot 5(1) \\
0(0)\end{array}$ & $\begin{array}{c}9 \cdot 0(13) \\
9 \cdot 6(5) \\
19 \cdot 7(12)\end{array}$ & $\begin{array}{l}9 \cdot 1(77) \\
25 \cdot 0(2) \\
0(0)\end{array}$ \\
\hline $\begin{array}{l}\text { Pipe-only smokers } \\
\leqslant 2 \text { ounces/week } \\
>2 \text { ounces/week }\end{array}$ & $\begin{array}{c}3 \cdot 4(1) \\
25 \cdot 0(14)^{\star \star}\end{array}$ & $\begin{array}{r}6 \cdot 7(1) \\
16 \cdot 7(2)\end{array}$ & $\begin{array}{c}7 \cdot 1(2) \\
23 \cdot 6(13)^{\star}\end{array}$ & $\begin{array}{c}0(0) \\
16 \cdot 7(2)\end{array}$ \\
\hline
\end{tabular}

${ }^{\star} \mathrm{p}<0.05,{ }^{\star \star} \mathrm{p}<0.01\left(\chi^{2}\right.$ test for differences in proportions among (1) cigar-only smokers between $\leqslant 2$ cigars/day and (i) 3-4 cigars/day and (ii) $>4$ cigars/day, and (2) pipe-only smokers between $\leqslant 2$ ounces/week and $>2$ ounces/week).
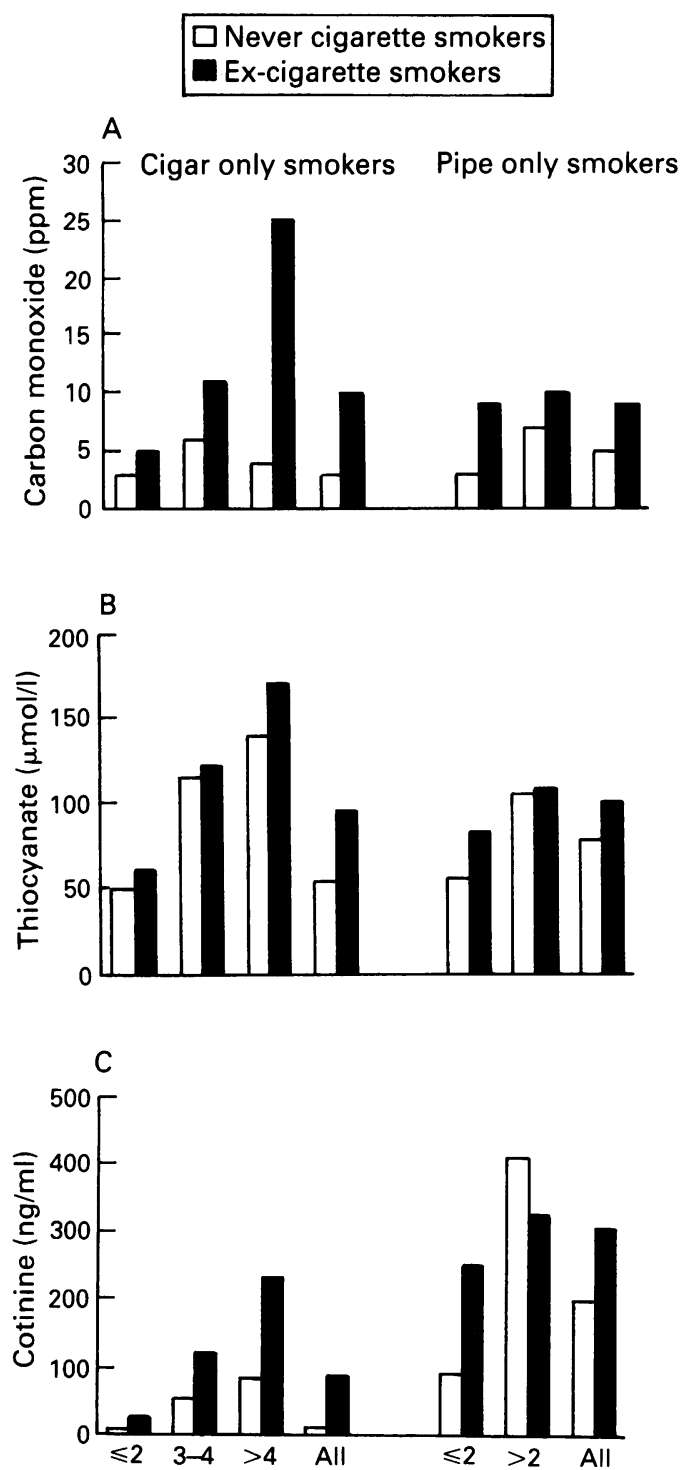

Daily cigar consumption Weekly pipe (number) consumption (ounces)

Figure Mean levels of $(A)$ carbon monoxide, $(B)$ thiocyanate, and (C) cotinine by cigar consumption and pipe consumption among ex-cigarette smokers and nevercigarette smokers.

group than in the light consumption group. Among pipe-only smokers there was a significant difference in the prevalence of both symptoms among those who previously smoked cigarettes, with a significantly higher ( $p<0.01$ and $p<0.05$ respectively) prevalence in the heavy consumption group than in the light consumption group. Light and moderate cigar smokers and light pipe smokers had a lower prevalence of symptoms than the control group. Among the never-cigarette smokers the prevalence of chronic cough and phlegm among heavy pipe smokers was higher than in light pipe smokers.

\section{Discussion}

This study shows that cigar and pipe smokers who are ex-cigarette smokers have an approximately 1.71 times higher prevalence of chronic cough and 1.63 times higher prevalence of chronic phlegm than those who have 
never smoked cigarettes. Cigar and pipe smokers who are never-cigarette smokers have an approximately 1.53 times higher prevalence of chronic cough, but the same prevalence of chronic phlegm.

Other studies investigating cough and phlegm among male cigar or pipe smokers have shown similar results. Comstock et $a l^{3}{ }^{3}$ in a small study of 230 subjects, found the prevalence of symptoms among cigar and pipe smokers to be about double that of nonsmokers. This study used the same age range as the SHHS. Densen et $a l^{2}$ in a study of over 3000 men, found approximately twice the prevalence of chronic cough and $50 \%$ higher prevalence of chronic phlegm among cigar and pipe smokers then in non-smokers using a wider age range than the SHHS. Haenszel and Hougen ${ }^{1}$ found the prevalence of persistent cough and phlegm to be almost three times the level of non-smokers in the 35-54 year age group, and double the prevalence in the 55-74 year age group (because of an increase in the prevalence of symptoms in the higher age group among the non-smokers). Cederlof et $\mathrm{al}^{4}$ found the prevalence of chronic cough to be approximately double, and the prevalence of chronic phlegm to be 1.7 times higher, for cigar and pipe smokers than for those who had never smoked.

The prevalence of chronic cough and phlegm among cigar and pipe smokers in the SHHS was approximately one third that of current cigarette smokers, which is similar to several studies where the prevalence of respiratory symptoms among current cigarette smokers was 2-3 times that of cigar and pipe smokers. ${ }^{1-4}$ These studies did not, however, assess cigar and pipe smoking separately.

Alderson et al ${ }^{10}$ found a 1.2 times higher risk of chronic bronchitis among cigar and pipe smokers than non-smokers. The risk among cigar and pipe smokers was approximately one third that among current cigarette smokers. Doll and Peto $^{8}$ in a large follow up study found cigar and pipe smokers to have nine times the mortality rate from chronic bronchitis than non-smokers, but this rate was just one third of the mortality rate of cigarette smokers. It was also shown that cigar and pipe smokers who previously smoked cigarettes had approximately twice the mortality rate from chronic bronchitis than those cigar and pipe smokers who had never smoked cigarettes. Similarly, in the SHHS ex-cigarette smokers who now smoked cigars or pipes had a higher prevalence of chronic cough and chronic phlegm than those cigar or pipe smokers who had never smoked cigarettes, although these differences were not significant. It was seen in the SHHS that, within 2-4 years of quitting smoking cigarettes, excigarette smokers (non-cigar or pipe smokers) had a similar prevalence of chronic respiratory symptoms to never-cigarette smokers. ${ }^{21}$ It may be that by switching to cigars, pipes, or both, symptoms continue in a number of individuals, perhaps because previous inhaling habits persist.

Dean et $a l^{9}$ examined cigar and pipe smok- ers separately and found the prevalence of respiratory symptoms to be very similar for never-smokers, cigar-only smokers, and pipeonly smokers. Only the prevalence of morning cough was found to be significantly higher among pipe-only smokers and cigar-only smokers than never-smokers, with cigar-only smokers having a higher prevalence than pipe-only smokers. A similar age group was used to the SHHS (37-67 years). Rimington ${ }^{6}$ studied pipe smokers only and found the prevalence of cough or phlegm to be almost double that of non-smokers (similar to the is findings of the SHHS) and closer to that of current cigarette smokers. Similarly, Ashford et $a l^{5}$ found pipe smokers had a higher prevalence of bronchitis than current smokers, although this was based on a study of coal miners where other risk factors may have contributed. Edwards $e t a l,{ }^{7}$ in a study of men aged 60-69 years, found the prevalence of a clinical diagnosis of chronic bronchitis to be $\vec{\omega}$ very similar between non-smokers and pipe smokers. In the SHHS it was seen that heavy pipe consumption resulted in a high prevalence of symptoms, but tobacco dosage was not studied in these other papers.

The accuracy of self reporting of respiratory symptoms may be of concern, although the MRC respiratory questionnaire is a widely used and reliable method for ascertaining the actual respiratory symptoms. ${ }^{22}$ Data on cigarette smoking history enabled us to assess the effect on symptoms of switching from cigarettes to cigars, pipes, or both. The data available on three biochemical markers of tobacco consumption allowed us to validate the self reported consumption levels of cigars and pipes. Further, with no questionnaire information on inhalation patterns we were still able to measure indirectly the inhalation patterns by examining the biochemical measures among ex-cigarette smokers and never-cigarette smokers at the same levels of daily cigar or pipe consumption.

The higher prevalence of respiratory symptoms among pipe smokers than non-smokers 은 may be caused by a large number of pipe $\frac{D}{O}$ smokers inhaling. Examination of the biochemical markers of tobacco consumption $N$ among pipe smokers in this study indicate $N$ that ex-cigarette smokers inhale more than $N$ never-cigarette smokers. Cowie et $\mathrm{al}^{23} \mathrm{~W}$ showed, by comparing carbon monoxide levels, that ex-cigarette smokers continue to inhale when switching from cigarettes to cig- on ars. Those ex-cigarette smokers who smoke 0 pipes have twice the prevalence of both respiratory symptoms than ex-cigarette smokers $\stackrel{D}{\overparen{D}}$ who smoke no tobacco product now $\underset{\mathbb{Q}}{\mathbb{Q}}$ ( $p<0.05$ for chronic cough), suggesting that they continue to inhale heavily. The preva- $\delta$ lence of chronic cough among pipe-only응 smokers is approximately twice that of nevercigarette smokers (although not statistically? significant). No difference is seen for chronic phlegm. The higher means of thiocyanate and, more especially, cotinine for pipe smokers than cigar smokers suggest a higher intake of tobacco products by pipe smokers which 
may explain the higher prevalences of the respiratory symptoms for pipe smokers than cigar smokers. However, pipe smokers still had prevalences of chronic cough and phlegm approximately half those of current cigarette smokers.

Cigar smokers who previously smoked cigarettes seem to inhale more than cigar smokers who have never smoked cigarettes. Pechacek et $a l^{24}$ found thiocyanate levels in cigar and pipe smokers to be higher in ex-cigarette smokers than in never-cigarette smokers which agrees with the findings in the SHHS. No appreciable difference in the prevalence of chronic cough and phlegm is seen between cigar-only and non-cigar/pipe smokers, however, suggesting that even the ex-cigarette smokers who smoke cigars are not inhaling enough to produce symptoms.

Few other papers have investigated the dose-response relationship between tobacco consumption among cigar and pipe smokers and the prevalence of cough and phlegm. Both Densen et $a l^{2}$ and Haenszel and Hougen $^{1}$ combined tobacco consumption for cigar and pipe smokers. They showed an increase in respiratory symptoms with increased tobacco consumption, in common with the SHHS which showed a positive dose-response effect for both cigar-only smokers and pipe-only smokers. This may be explained partly by the fact that heavy cigar smokers and heavy pipe smokers who previously smoked cigarettes had a higher former daily cigarette consumption than light cigar and light pipe smokers.

A surprising finding among ex-cigarette smokers in this study is that light pipe smokers and light to moderate cigar smokers have slightly lower prevalences of chronic cough and phlegm than never-smokers. This seems to be at variance with the results of both Haenszel and Hougen ${ }^{1}$ and Densen et $a l^{2}$ who both found their light cigar/pipe consumption group to have higher prevalences than never smokers. However, both these previous studies used higher cut off points for "light" consumption than were used in our study, at least for pipe smoking where it is possible to make comparisons. The most likely explanation for the relatively low prevalences among the low consumption groups in this study is sampling variation: the differences between light pipe and light to moderate cigar smokers among ex-cigarette smokers (from table 3) are always not significant $(p>0 \cdot 10)$.

The main conclusion from this study is that, although not all symptom prevalences were significantly higher in cigar or pipe smokers than in non-smokers, the trends in the data demonstrate that cigar and pipe smokers have a higher prevalence of both chronic cough and chronic phlegm than those who have never smoked. Among cigar and pipe smokers, ex-cigarette smokers have a higher prevalence of symptoms than nevercigarette smokers and higher biochemical measures of smoking which suggest that their symptoms may be due to continued inhalation of smoke. The prevalence of chronic symptoms was lower in cigar and pipe smokers than in cigarette smokers, but cigar or pipe smoking is still associated with appreciable morbidity in terms of cough and phlegm production.

The Scottish Heart Health Study was funded by the Scottish Office: Home and Health Department, and the smoking component by the Tobacco Products Research Trust. The opin ions expressed are those of the authors and not the funding body.

1 Haenszel W, Hougen A. Prevalence of respiratory symptoms in Norway. $\mathcal{F}$ Chronic Dis 1972;25:519-44.

2 Densen PM, Jones EW, Bass HE, Breuer J. A survey of respiratory disease among New York City postal and transit workers. 1. Prevalence of symptoms. Environ Res 1967;1:265-86.

3 Comstock GW, Brownlow WJ, Stone RW, Sartwell PE Cigarette smoking and changes in respiratory findings. Arch Environ Health 1970;21:50-7.

4 Cederlof R, Friberg L, Hrubec Z. Cardiovascular and respiratory symptoms in relation to tobacco smoking. Arch Environ Health 1969;18:934-40.

5 Ashford JR, Brown S, Duffield DP, Smith CS, Fay JWJ The relation between smoking habits and physique, respiratory symptoms, ventilatory function, and radiological pneumoconiosis amongst coal workers at three Scottish collieries. Br f Prev Soc Med 1961;15:106-17.

6 Rimington J. Chronic bronchitis, smoking and social class. A study among working people in the towns of mid and east Cheshire. Br $\mathcal{F}$ Dis Chest 1969;63:193-205.

7 Edwards F, McKeown T, Whitfield AGW. Association between smoking and disease in men over sixty. Lancet 1959;i:196-200.

8 Doll $R$, Peto $R$. Mortality in relation to smoking: 20 years' observations on male British doctors. $B M \mathcal{F} 1976 ; 2$ : 1525-36.

9 Dean G, Lee PN, Todd GF, Wicken AJ, Sparks DN. Factors related to respiratory and cardiovascular symptoms in the United Kingdom. F Epidemiol Community Health 1978;32:86-96.

10 Alderson MR, Lee PN, Wang R. Risks of lung cancer, chronic bronchitis, ischaemic heart disease, and stroke in relation to type of cigarette smoked. $\mathcal{f}$ Epidemio Community Health 1985;39:286-93.

11 Smith WCS, Tunstall-Pedoe H, Crombie IK, Tavendale $R$. Concomitants of excess coronary deaths. Major risk factor and lifestyle findings from 10,359 men and women in the Scottish Heart Health Study. Scott Med $\mathcal{F}$ 1989;34:550-5.

12 Tunstall-Pedoe H, Smith WCS, Crombie IK, Tavendale R. Coronary risk factors and lifestyle variation across Scotland: results from the Scottish Heart Health Study. Scott Med f 1989;34:556-60.

13 Smith WCS, Crombie IK, Tavendale R, Irving JM, Kenicer MB, Tunstall-Pedoe $H$. The Scottish Heart Health Study: objectives and development of methods. Health Bull 1987;45:211-7.

14 Florey C du V, Leeder SR. Methods for cohort studies of chronic airflow limitation. Copenhagen: World Health Organisation, 1982.

15 Rose GA, Blackburn H, Gillum RF, Prineas RJ. Cardiovascular survey methods. Geneva: World Health Organisation, 1982.

16 Office of Population Censuses and Surveys. Classification of occupations 1980. London: HMSO, 1980.

17 Irving JM, Clark EC, Crombie IK, Smith WCS Evaluation of a portable measure of expired air carbon monoxide. Prev Med 1988;17:109-15.

18 Woodward $M$, Tunstall-Pedoe $H$. Do smokers of lower tar cigarettes consume lower amounts of smoke components? Results from the Scottish Heart Health Study. Br $\mathcal{F}$ Addict 1992;87:921-8.

19 Woodward $M$, Tunstall-Pedoe $\mathrm{H}$. An iterative technique for identifying smoking deceivers with application to the Scottish Heart Health Study. Prev Med 1992;21:88-97.

20 Armitage P, Berry G. Statistical methods in medical research. Oxford: Blackwell, 1987

21 Brown CA, Crombie IK, Smith WCS, Tunstall-Pedoe $H$ The impact of quitting smoking on symptoms of chronic bronchitis: results of the Scottish Heart Health Study. Thorax 1991;46:112-6.

22 Witney CH, Price CE, Swan AV, Papacosta AO, Hensley MJ. Repeatability of a questionnaire to assess respiratory symptoms in smokers. F Epidemiol Community Health 1988;42:54-9.

23 Cowie J, Sillett RW, Ball KP. Carbon monoxide absorption by cigarette smokers who change to smoking cigars. Lancet 1973; i: 1033-5.

24 Pechacek TF, Folsom AR, Gaudermaris R de, Jacobs DR, Luepker RV, Gillum RF, et al. Smoke exposure in pipe and cigar smokers. Serum thiocyanate measures. $\mathfrak{Y A M A}$ 1985;254:3330-2. 